Bulletin of the Seismological Society of America. Vol. 57, No. 5, pp. 1017-1023. October, 1967

\title{
THE ALASKA EARTHQUAKE OF 28 MARCH 1964: A COMPLEX MULTIPLE RUPTURE
}

\author{
By MaX Wyss and James N. Brune
}

\begin{abstract}
The seismograms of the Alaskan earthquake of 28 March 1964 are characterized by multiple $P$-phases not predicted by the travel-time curves.

Seismograms with low magnifications from 80 stations covering distances from $40^{\circ}$ to $90^{\circ}$ and a wide range of azimuths were analyzed. The character of the $P$-wave portion of the seismograms is interpreted in terms of an approximate multiple-event source mechanism where the propagating rupiure triggers larger distinct events. Six events were located using the Gutenberg sine-curve method. The times after the initial origin time were $9,19,28,29,44$ and 72 sec respectively, and the events were located $35,66,89,93,165$ and $250 \mathrm{~km}$ away from the initial epicenter. Dividing the distance by the delay-time gives an average rupture velocity of $3.5 \mathrm{~km} / \mathrm{sec}$.
\end{abstract}

\section{INTRODUCTION}

The region of energy release during large shallow earthquakes, as determined from the distribution of aftershocks, surface rupture and long-period surface-wave radiation, is of the order of 500 to $1000 \mathrm{~km}$ length. However, the nature of energy release that occurs in this zone is not well understood. Surface wave radiation suggests that the gross pattern of energy release is like a propagating source (Benioff, 1955; Benioff et al., 1961; Ben-Menahem, 1961; Ben-Menahem and Toksoz, 1962, 1963; Press et al., 1961) with velocity of about $3 \mathrm{~km} / \mathrm{sec}$, but the long wavelengths used lack the resolution to determine the details of the release, in particular whether it is smooth or erratic. Body waves from large earthquakes often suggest a complicated pattern of energy release. (Vesanen, 1942; Usami, 1956; Richter, 1958; Miyamura et al., 1964; Băth, 1965). In this paper the $P$-wave portion of seismograms from the Alaskan earthquake of March 28, 1964 are studied in detail and interpreted in terms of a multiple source in order to better understand the nature of energy release during large earthquakes.

\section{DATA}

Seismograms from low magnification instruments at 70 stations were collected. The instrument types used were Wiechert, JMA 59, WWNSS, Milne-Shaw and Galitzin. The stations covered a wide range of azimuths and distances ranging from $40^{\circ}$ to $90^{\circ}$. The azimuth distribution, however, was not even since stations are concentrated in Europe, North and South America and Japan. Figure 1 shows records from stations in Europe, Mexico and Japan. Arrows point out six of the most outstanding phases. These phases do not correspond to any of the phases predicted by standard travel-time curves. The amplitude of the first arrival is much smaller than that of the following phases. The average magnitude* corresponding

* All magnitudes are $\mathrm{m}_{\mathrm{b}}$. 
to the very first $P$-pulse determined from WWNSS stations, is 6.6. Phases with successively larger amplitudes follow the first event. The magnitude determined for the largest amplitudes in the $P$-wave train, occurring about 60 seconds after the first arrival, is 7.8. This value agrees approximately with the corresponding magnitudes determined from surface waves (7.8) and $S$ waves (8.1) using the conversion formula between surface-wave magnitude and body-wave magnitude given by Richter (1958). The character of the first two minutes of the seismograms cannot be explained by either second arrivals of a simple point source or a simple smoothly propagating rupture. Therefore, a more complex source is necessary and the records

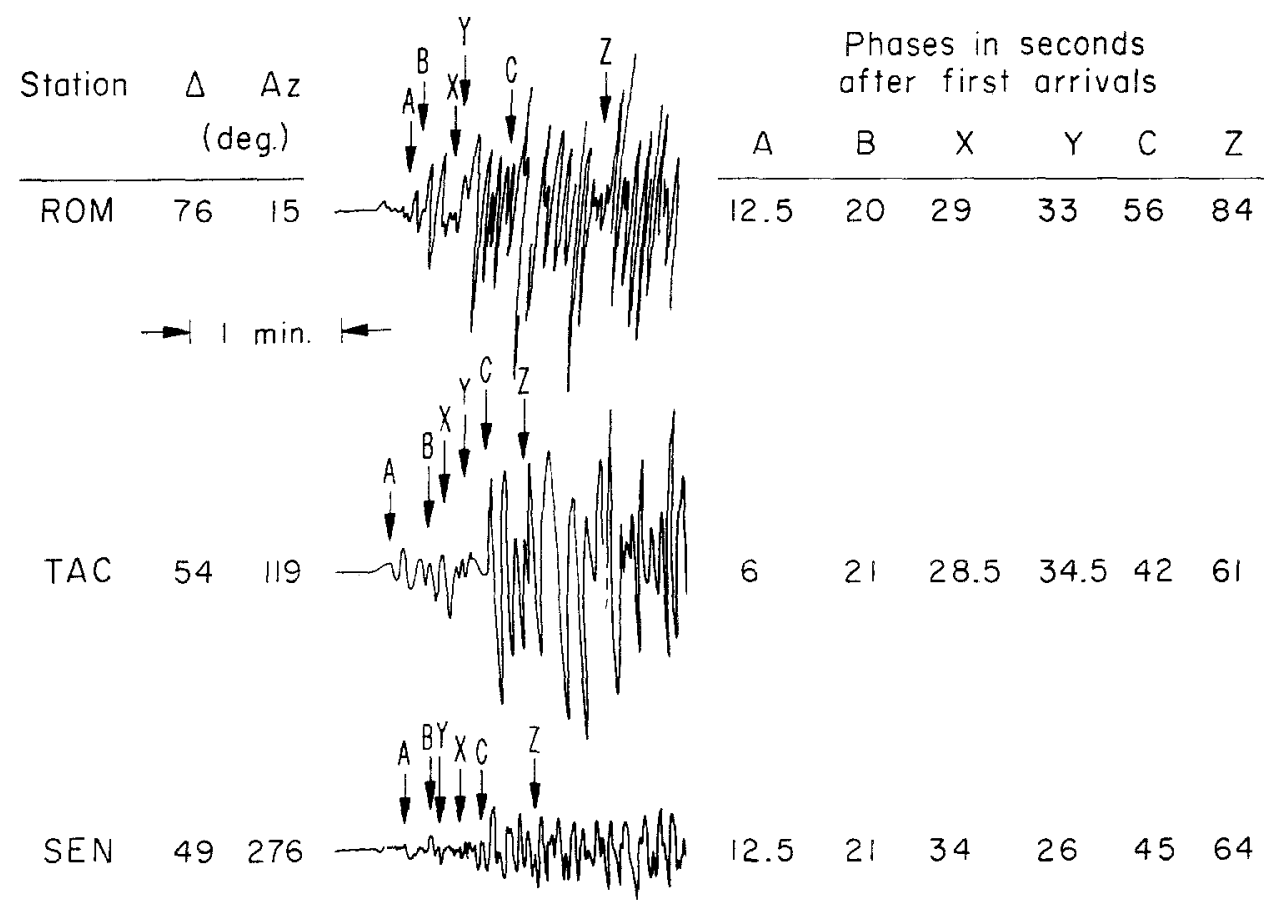

Fig. 1. $P$-wave portion of seismograms from Europe, Mexico and Japan. Arrows point out the phases attributed to the six determined events. The table on the right gives the time-lags of the phases with respect to the first arrivals.

suggest that the source might be approximated by a series of point sources distributed in space and time.

\section{ANALYsis}

In order to establish the distribution of events for the multiple point-source approximation, all outstanding phases in the first two minutes of the seismograms were read. For each station a list of time lags with respect to the first arrival resulted. The criteria for picking a time lag were a sudden substantial increase in amplitude and an abrupt change in phase. The stations were ordered in azimuth for comparison of their time-lag sequences. The largest and most obvious pulse, event $\mathrm{C}$ on Figure 1, could be identified and correlated between the stations of 
different azimuth without difficulty. The other pulses were harder to correlate. The time lag with which they appear on the records is a function not only of sourcetime and position differences, but also of the azimuth and distance of the stations. In order to aid in further correlation a model of a propagating rupture spreading out in a horizontal plane with a velocity of $3.3 \mathrm{~km} / \mathrm{sec}$ was assumed. A tentative correlation was then made by computing the approximate distance from the initial epicenter under these assumptions. The approximate distance is given by:

$$
\Delta_{i}=\frac{t_{i}}{\frac{1}{\beta}+\cos (\theta-\phi) \frac{d p}{d \Delta}}
$$

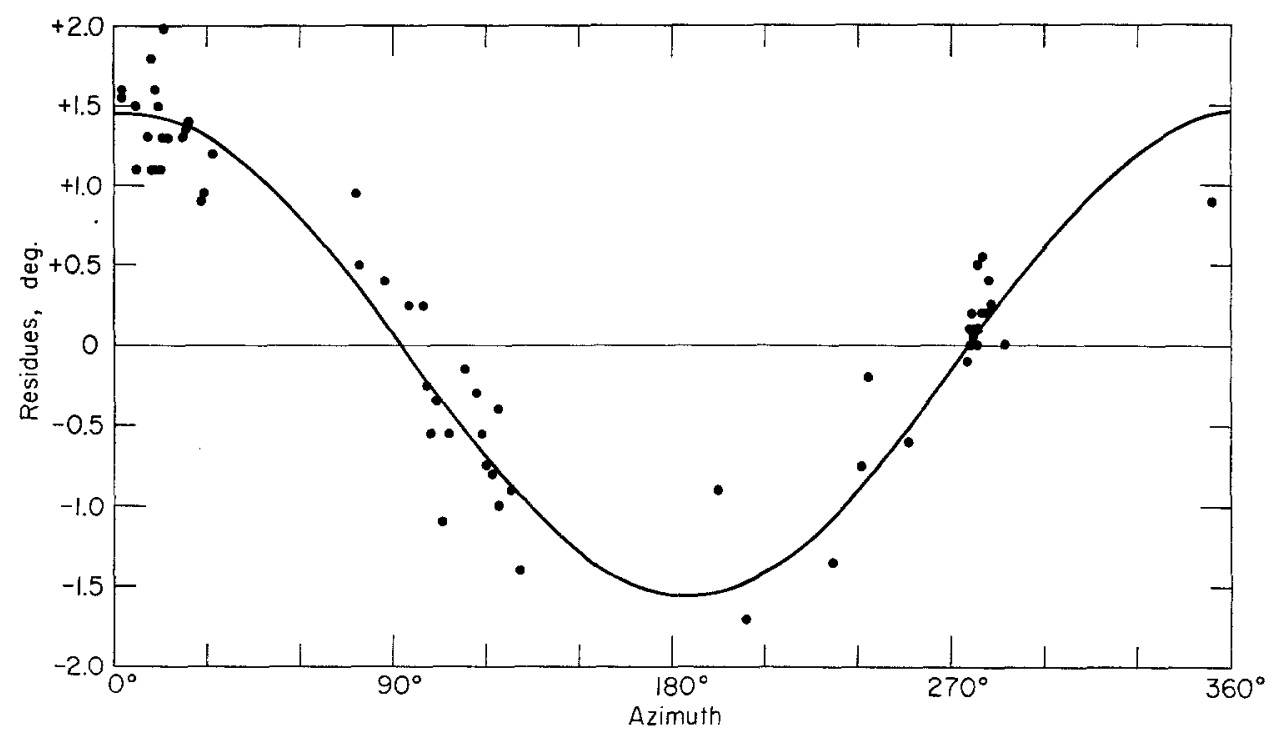

FIG. 2. Sine-curve plot for the location of event C. Standard deviation $22 \mathrm{~km}$.

$t_{i}=$ seconds after first arrival, read from the seismograms,

$\beta=$ propagating velocity of rupture, assumed,

$\frac{d p}{d \Delta}=$ slope of travel-time curve,

$\theta=$ azimuth from the initial epicenter to station,

$\phi=$ azimuth from the event to initial epicenter, parameter.

The distances $\Delta_{i}$ were computed from the time lags of several stations at different azimuths and distances, under variation of the parameter $\phi$, the propagation direction. For different $\phi$, different combinations of time lags could give more or less concordant results for the distance $\Delta_{i}$. For combinations of time lags that were concordant, relocation of the epicenters of the corresponding events using the Gutenberg sine-curve method, was carried out with all available readings. In Figure 2 the distance residues for the location of event $C$ are plotted as a function of azimuth. The reliability of certain combinations of time lags is indicated by the scattering of the residues of the Gutenberg sine-curve method. Incorrect combinations made it impossible to fit a sine-curve. 
After detailed analysis of the records, using the above procedure, 6 events denoted by A, B, C, X, Y, and $\mathrm{Z}$ were identified. Epicenters for the events A, B, and $\mathrm{C}$ are well-established for the following reasons: (1) The standard deviation for the sine-curve fit is small; (2) These events are represented by conspicuous pulses on 90 to 95 per cent of the analyzed records; (3) Their locations lie within the zone of aftershocks; and (4) The delay times from the initial epicenter give quite reasonable rupture velocities, about $3.5 \mathrm{~km} / \mathrm{sec}$.

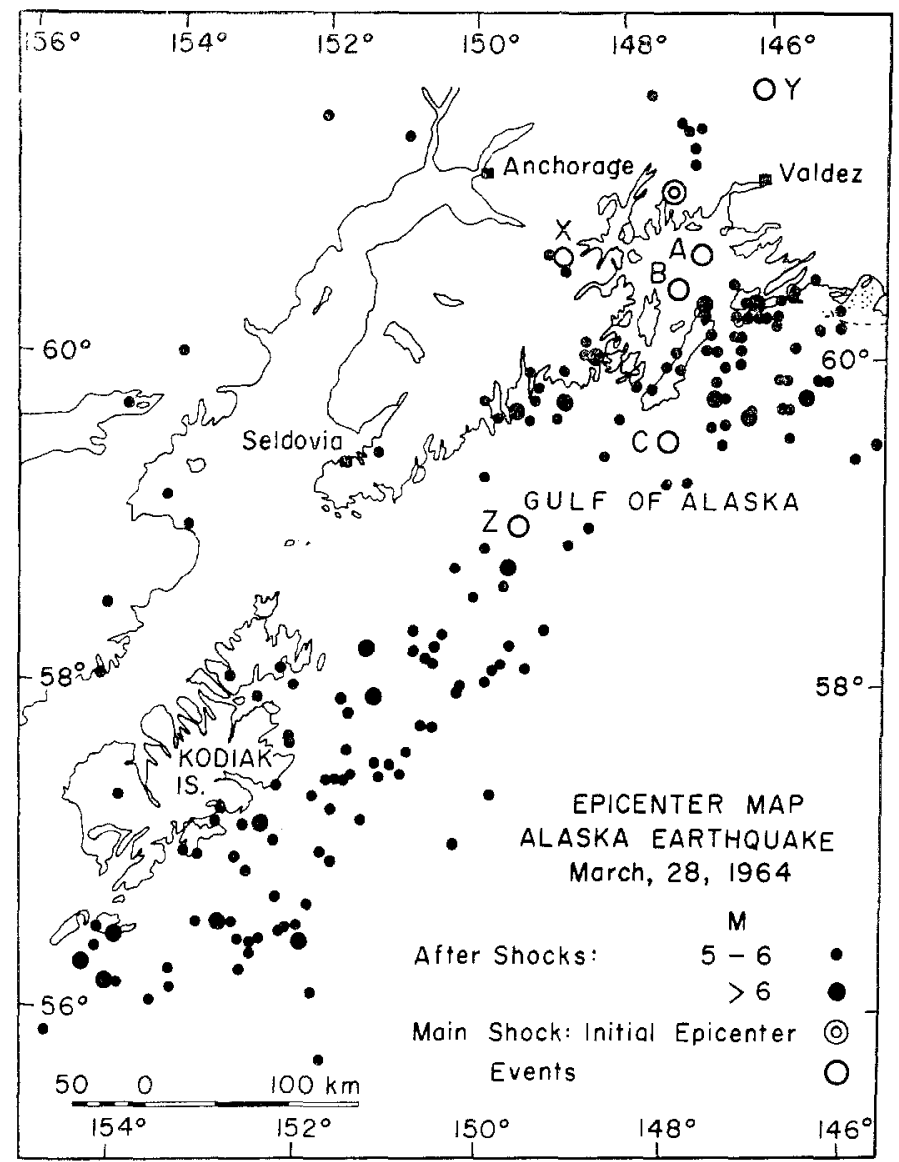

FIG. 3. Epicenter map showing locations of six events A, B, C, X, Y and Z. Aftershocks according to Algermissen (1966).

The events $\mathrm{X}, \mathrm{Y}$, and $\mathrm{Z}$ are presented here as possible additional events with a somewhat lower degree of confidence. They could be identified on 60 to 75 per cent of the analyzed recorc's. Because of very high amplitudes and complexity of the signal no further events could be established beyond 80 sec after the first arrival, although they very probably occurred.

\section{Discussion}

The preceding analysis has indicated that the energy release during the Alaskan earthquake was characterized by more or less distinct high amplitude bursts or 
events, possibly superimposed on a smaller continuous level of energy release associated with a propagating wave and/or rupture. This is consistent with Haskell's (1964) conclusion that large earthquakes must have erratic source-time functions since a simple moving source does not radiate as much short-period energy as is observed. The events could represent consecutive bifurcation points caused by the rupture velocity accelerating to a limiting value as suggested by Mansinha (1964). If his calculations would apply for the studied earthquake, the velocity of transverse waves in the source region would be obtained by dividing the rupture velocity of $3.5 \mathrm{~km} / \mathrm{sec}$ by a factor of about 0.7 . The resulting transverse wave velocity of $5.0 \mathrm{~km} / \mathrm{sec}$ would indicate that the source region is to be placed in the upper mantle rather than the crust. The aftershocks, on the other hand, occurred at an average depth of $22 \mathrm{~km}$ and our study appears to be consistent with the thrust fault model put forward by Plafker (1965) and Savage and Hastie (1966). The strongest event of the described series, event $\mathrm{C}$, is located only $40 \mathrm{~km}$ from the zone of maximum uplift in model 3 given by Savage and Hastie (1966). This raises the question as to whether event $\mathrm{C}$ represents a breakout-phase (Savage, 1965). A fault plane dipping

TABLE 1

\begin{tabular}{crrr}
\multicolumn{4}{c}{ Rutture Propagation Vetuocity } \\
\hline Event & $\begin{array}{c}\text { Time } \\
\text { lag } \\
\text { [sec] }\end{array}$ & $\begin{array}{c}\text { Distance to } \\
\text { initial event } \\
\text { [km] }\end{array}$ & $\begin{array}{c}\text { V } \\
{[\mathrm{km} / \mathrm{sec}]}\end{array}$ \\
\hline A & 9 & 35 & 3.9 \\
B & 19 & 66 & 3.5 \\
C & 44 & 165 & 3.8 \\
X & 28 & 89 & 3.1 \\
Y & 29 & 93 & 3.2 \\
Z & 72 & 250 & 3.5
\end{tabular}

Average propagation velocity: $\bar{V}=3.5 \mathrm{~km} / \mathrm{sec}$.

$9^{\circ} \mathrm{NW}$ and having a depth of about $22 \mathrm{~km}$ at the original epicenter would intersect the surface in the region of event $\mathrm{C}$. The resulting difference in depth of event $\mathrm{C}$ with respect to the original epicenter, $20 \mathrm{~km}$, leads to a decrease of the time delay as determined from the time lags on the seismic records. The distance from the original epicenter remains in first order the same, so the rupture velocity deduced from event $\mathrm{C}$ is then increased to about $4 \mathrm{~km} / \mathrm{sec}$. Alternatively, event $\mathrm{C}$ may be a stopping phase representing the end of the southward rupture.

The sequence of events started out from the initial epicenter location. During the first 44 sec events apparently occurred at various azimuths. Event $Y$ perhaps represents a stopping phase for the northerly direction of propagation. After event $\mathrm{C}$ the sequence continued $600 \mathrm{~km}$ in a southwesterly direction to the south tip of Kodiak Island. The last event that could be identified, event Z, lies $250 \mathrm{~km}$ from the initial rupture and occurred 72 sec later (Figure 3). Later events probably occurred southwest of the event $Z$, but could not be identified because of the complexity of the seismograms.

The standard deviation of the distance residues for the Gutenberg sine-curve location of the epicenters was 0.2 degrees $(22 \mathrm{~km})$. Considering the complexity of 
the analyzed records, this standard deviation is quite satisfactory. The locations and time lags give velocities between 3.1 and $3.9 \mathrm{~km} / \mathrm{sec}$ for a disturbance radiating from the origin and triggering events (Table 1). The average southwesterly component of the propagation velocity is about $3.2 \mathrm{~km} / \mathrm{sec}$ and thus the velocities determined in this manner agree approximately with those determined from the directivity of the surface wave radiation pattern for this earthquake (Furumoto, 1965). The values of the rupture velocity can be varied somewhat if variations in depth relative to the first shock are allowed.

The pulses representing events $\mathrm{A}, \mathrm{B}$, and $\mathrm{C}$ on the records are compared to the initial pulse in the average 6,12 , and 30 times larger respectively, corresponding to a magnitude increase from approximately 6.6 to 7.8. In Figure 3 it appears that the events are not surrounded by aftershocks in their immediate vicinity. This suggests that the strain was released in the vicinity of the events so that there was no strain-energy left for aftershocks.

\section{Conclusions}

(1) The Alaskan earthquake of March 28, 1964 ruptured in a series of events. This is probably the case for many other larger earthquakes.

(2) The rupture propagated initially in various azimuthal directions but after a time of about 44 sec continued only in a southwesterly direction.

(3) The average propagation velocity obtained by dividing the distances of the event-epicenters from the original epicenter by the corresponding time delays was $3.5 \mathrm{~km} / \mathrm{sec}$.

(4) The amount of energy represented by discrete events is much greater than the energy which can be attributed to continuous radiation.

\section{ACKNOWLEDGMENTS}

We wish to thank all those who cooperated by sending seismograms of the Alaskan earthquake. This study was supported by National Science Foundation Grant GP 2806.

\section{REFERENCES}

Algermissen, S. T. (1966). Seismic studies in Alaska, ESSA Symposium on Earthquake Prediction, U. S. Department of Commerce.

Båth, M. (1965). Seismological Bulletin, Uppsala, February 4.

Benioff, H. (1955). Mechanism and strain characteristies of the White Wolf fault as indicated by the aftershock sequence, California Div. Mines Bull. 171, 199-202.

Benioff, H., F. Press and S. Smith (1961). Excitation of the free oscillations of the earth by earthquakes, J. Geophys. Res. 66, 605-619.

Ben-Menahem, A. (1961). Radiation of seismic surface waves from finite moving source, Bull. Seism. Soc. Am. 51, 401-435.

Ben-Menahem, A. and M. N. Toksoz (1962). Source mechanism from spectra of long-period surface waves, $J$. Geophys. Res. 67, 1543-1955.

Ben-Menahem, A. and M. N. Toksoz (1963). Source mechanism from spectra of long-period seismic surface waves, 3. the Alaskan earthquake of July 10, 1958, Bull. Seism. Soc. Am., $53,905-919$.

Furumoto, A. S. (1965). Source mechanism study of the Alaskan earthquake and Tsunami of 27 March 1964, Part II: Analyses of Rayleigh wave, Report HIG-65-17 of the Hawaiian Inst. of Geophys.

Haskell, N. A. (1964). Total energy and energy spectral deasity of elastic wave radiation from propagating faults, Bull. Seism. Soc. Am., 54, 1811-1841. 
Mansinha, L. (1964). The velocity of shear fracture, Bull. Seism. Soc. Am. 54, 369-376.

Miyamura, S., S. Omote, R. Teisseyre and E. Vesanen (1964). Multiple shocks and earthquake series pattern, Bull. of the Int. Inst. of Seismology and Earthquake Eng. 2, 71-92.

Plafker, G. (1965). Tectonie deformation associated with the 1964 Alaskan earthquake, Science, $148,1675-1687$.

Press, F., A. Ben-Menahem and N. Toksoz (1961). Experimental determination of earthquake fault length and rupture velocity, $J$. Geophys. Res. 66, 3471-3485.

Press, F. and D. Jackson (1965). Alaskan earthquake, 27 March 1964: Vertical extent of faulting and elastic strain energy release, Science, 147, 867-868.

Press, F. (1965). Displacements, strains and tilts at teleseismic distances, J. Geophys. Res. 70, 2395-2412.

Richter, C. F. (1958). Elementary Seismology, Freeman, San Francisco.

Savage, J. C. (1965). The stopping phase on seismograms, Bull. Seism. Soc. Am. 55, 47-58.

Savage, J. C. and L. M. Hastie (1966). Surface deformation associated with dip-slip faulting, $J$. Geophys. Res. 71, 4897-4904.

Stauder, W. and G. A. Bollinger (1966). The focal mechanism of the Alaskan earthquake of March 28, 1964 and its aftershock sequence, $J$. Geophys. Res. 71, 5283-5296.

Usami, T. (1956). Seismometrical study of Boso-Oki earthquake of November 26, 1953, Quart. Jour. Seismology, 21, 1-13.

Vesanen, Eijo (1942). Ueber die Typenanalytische Auswertung der Seismogramme, Ann. Acad. Sci. Fenn. AIII, 5.

SEISMOLOGICAL Laboratory

California Institute of Technologx

Pasadena, Californta

Drvision of Geological Sciences

Contribution No. 1458.

Manuscript received April 14, 1967. 